\title{
Anti-TIM-3 Monoclonal Antibody INCAGN02390
}

National Cancer Institute

\section{Source}

National Cancer Institute. Anti-TIM-3 Monoclonal Antibody INCAGN02390. NCI

Thesaurus. Code C162625.

A fully human Fc-eng ineered immunoglobulin G1 kappa (IgG1 kappa) antibody directed ag ainst the inhibitory $\mathrm{T}$-cell receptor $\mathrm{T}$-cell immunog lobulin and mucin domain-containing protein 3 (TIM-3; TIM3; hepatitis A virus cellular receptor 2; HAVCR2), with potential immune checkpoint inhibitory and antineoplastic activities. Upon administration, INCAGN02390 forms a high-affinity interaction with TIM-3 expressed on certain T-cells, thereby preventing the engagement of TIM-3 by its ligands, phosphatidylserine (PtdSer) and galectin-9. This abrog ates T-cell inhibition, activates antigen-specific T-lymphocytes and enhances cytotoxic T-cell-mediated tumor cell lysis, which results in a reduction in tumor cell proliferation. Additionally, INCAGN02390 elicits TIM-3 receptor internalization, potentially preventing interactions with other ligands.TIM-3, a transmembrane protein and immune checkpoint receptor expressed on certain lymphocytes, including tumor infiltrating lymphocytes (TILs), is associated with tumor-mediated immune suppression. 